\title{
Rediscovery of Piranthus decorus Thorell 1895 (Araneae: Salticidae) after 122 years since the original description
}

\author{
John T. D. Caleb ${ }^{1 *} \&$ Rajesh V. Sanap ${ }^{2}$ \\ ${ }^{1}$ Zoological Survey of India, Prani Vigyan Bhawan, M-Block, New Alipore, Kolkata-700 053, West Bengal, India \\ E-mail: caleb87woodgate@gmail.com \\ ${ }^{2}$ National Centre for Biological Sciences, Tata Institute of Fundamental Research, \\ Bangalore-560 065, Karnataka, India \\ *Corresponding author
}

\begin{abstract}
Piranthus decorus Thorell 1895 is recorded for the first time in India. This species has never been rediscovered for 122 years since it was described as a new genus and species. Detailed diagnostic illustrations and photographs are provided along with map.
\end{abstract}

Key words - Araneae, jumping spider, Piranthus, new record, taxonomy, Mumbai, India

\section{Introduction}

The jumping spider genus Piranthus was erected by Thorell (1895). Presently the genus consists of 2 valid species: P. casteti Simon 1900 from India and P. decorus Thorell 1895 from Burma (Myanmar) (Prószyński 2016; World Spider Catalog 2017). P. decorus has never been reported for 122 years since the original description. Recently, one of the authors (RS) photographed an unknown male specimen from the Aarey Milk Colony, an ecosensitive dry deciduous jungle in Mumbai, but the specimen was not collected. Eventually we found a similar looking female specimen during a follow-up survey in the same locality, and identified it with $P$. decorus on the basis of the illustrations by Prószyński (1984). The present paper provides a record and a description of this species after a long gap. We believe that this record provides a glimpse of the largely unexplored salticid diversity and would add considerably to the knowledge on Indian salticidae.

\section{Materials and methods}

Specimen was hand collected and photographed using Canon DSLR 60D, $60 \mathrm{~mm}$ lens with Canon Speedlite 430 EX II external flash. The specimen was preserved in $70 \%$ ethanol and examined using a Leica S8APO stereoscopic microscope. Microphotographs were obtained using Leica MC120 HD camera attached to stereoscopic microscope with LAS core software package. All measurements are in millimeters. Leg measurements are given as: total length (femur, patella, tibia, metatarsus, tarsus). Spine positions are as follows: prolateral, dorsal, retrolateral and ventral. Species was identified with the help of illustrations of the type provided by Prószyński $(1984 ; 2016)$. Specimen is deposited in the research collections of the National Centre for Biological Sciences (NCBS), Bangalore (=Bengaluru), Karnataka. Abbreviations used: $\mathrm{ALE}=$ anterior lateral eye, $\mathrm{AME}=$ anterior median eye $\mathrm{PLE}=$ posterior lateral eye, $\mathrm{PME}=$ posterior median eye.

\section{Taxonomy}

Genus Piranthus Thorell 1895

Piranthus decorus Thorell 1895

(Figs. 2A-F, 3A-B, 4A-D, 5)

Piranthus decorus Thorell 1895: 339 (D) ); holotype not examined.

Piranthus decorus: Prószyński 1984: 111.

Note. Although Thorell (1895) mentioned only "Tharrawaddy" as the locality of this species, according to Prószyński (1984) the female collected from "Palon" is holotype (Fig. 1).

Material examined. Female (NCBS-AW274) from Aarey Milk Colony, (198 $\left.37.4922^{\prime \prime} \mathrm{N}, 72^{\circ} 52^{\prime} 51.459^{\prime \prime} \mathrm{E}\right)$ Alt $61 \mathrm{~m}$, Mumbai, Maharashtra, India, 21 June 2016, leg. Rajesh V. Sanap.

Diagnosis. The species can be distinguished from its only congener $P$. casteti Simon 1900 by the presence of a small circular depression in the slightly raised posteriomedial plate of the epigyne (not seen in $P$. casteti) (Figs. 2E, $3 \mathrm{~A}$ ); copulatory ducts emerge from the openings laterally and run down subparallel (ducts move inwards making sshaped bends in P. casteti) (Figs. 2F, 3B).

Description. Female. Total length: 7.68, carapace: 4.24 long, 3.09 wide. Eye diameter: AME 0.73, ALE 0.31, PME 0.13, PLE 0.29. Eye interdistances: AME-AME 0.09; 


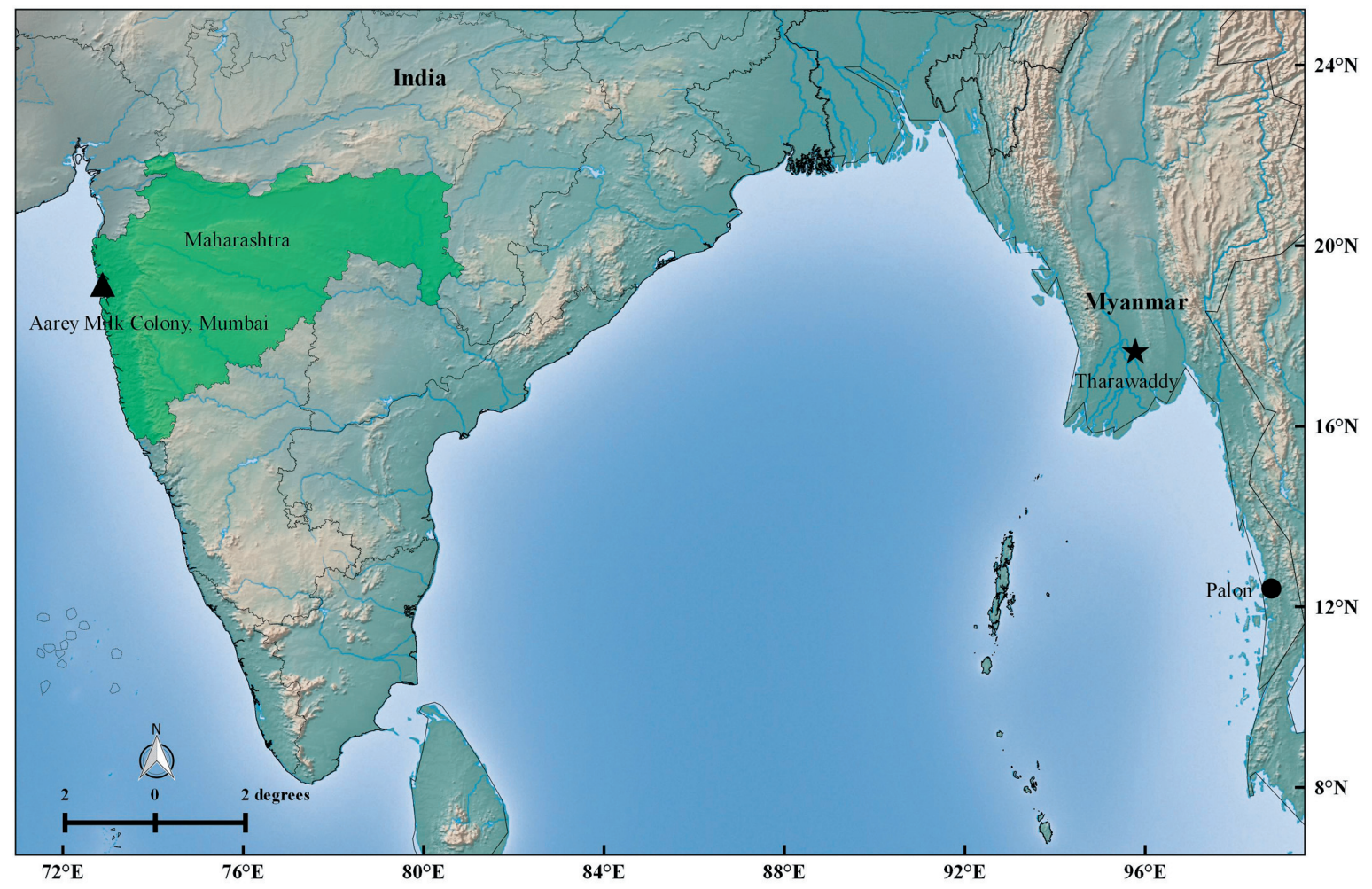

Fig. 1. Map showing distributional records of Piranthus decorus Thorell 1895. Records from Myanmar: circle — type locality; star — additional specimen record. Record from India: triangle — new record.

AME-ALE 0.07; ALE-PME 0.41; PME-PME 2.14; PMEPLE 0.71; PLE-PLE 1.88. Leg measurements: I 6.05 (1.89, $1.41,1.25,0.91,0.59)$; II $5.57(1.73,1.33,1.06,0.84,0.61)$; III 4.98 (1.58, 0.93, 0.76, 1.07, 0.64); IV 6.75 (1.98, 1.15, $1.43,1.55,0.64)$. Leg formula: 4123 . Leg spination: femora I 0200; II 0300, III 0400, IV 0400; tibiae I 0003, II 0002, III 0000, IV 0000; metatarsi I 0004, II 0004, III 0000, IV 0000. Abdomen: 3.44 long, 1.73 wide.

Carapace black, rugulose; covered with long black hairs and white scales scattered intermittently. Eye field flat dorsally with a swelling along each inner margin of PLE (Figs. $\left.2 \mathrm{~A}^{-} \mathrm{C}, 4 \mathrm{~A}^{-} \mathrm{B}, \mathrm{D}\right)$. Anterior eyes surrounded by white orbital setae; regions posterior to ALEs and lateral margins of carapace covered by white setae. Clypeal region with dense long white hairs (Fig. 4B). Sternum reddish brown. Chelicerae reddish brown, dorsally covered by white hairs; pluridentate with 3 large promarginal and a row of 7 small retromarginal teeth. Labium and maxillae brown with paler inner margins (Fig. 2D). Legs I \& II enlarged; leg I with reddish brown femur and black tibia with orangish distal region, other segments orangish yellow; legs II-IV orangish yellow; all legs covered with thick setae (Figs. 4A-B). Abdomen elongated oval; blackish brown, covered with white hairs; a broad, longitudinal median yellowish patch present, and with a tuning fork shaped thin black marking along the midline (Figs. 2A, 4A); anterior margin covered with white hairs which run along the lateral margins of the abdomen. Spinnerets blackish brown. Epigyne: anterolateral copulatory openings placed in large oval grooves separated by a thin median septum; posterior sclerotized plate with a median circular depression (Figs. 2E, 3A). Ducts run posteriorly leading to postero-medially placed spermathecae (Figs. 2F, 3B).

Color of living individual (Figs. 4A-D). Pedipalps light orange covered with white hairs and some white scales. Legs orange except brownish femur I; black tibia I with orange distal part and brownish metatarsus IV. White hairs present on lateral margins of all legs; leg I and II with white dorsal hairs at the distal region of tibia and proximal region of metatarsus. Abdomen with a greenish yellow dorsal marking. White hairs cover the spinnerets dorsally.

Male. Unknown.

Distribution. Myanmar (Palon, Tharrawaddy); India (Mumbai) new record.

Additional photographic records. In addition to the above specimen, three photographs of a male specimen from the same locality are available (Fig. 5; Aarey Milk Colony, 11 August 2015, Rajesh V. Sanap). We presume that these images correspond to the conspecific male of the species since it has a strikingly similar general morphology and coloration, moreover they were taken from the same locality. 
A

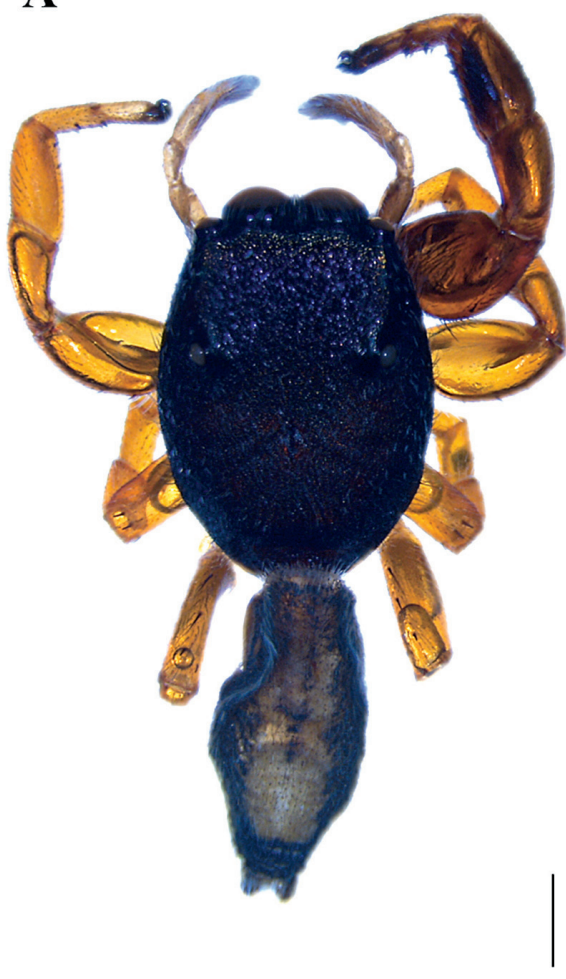

B

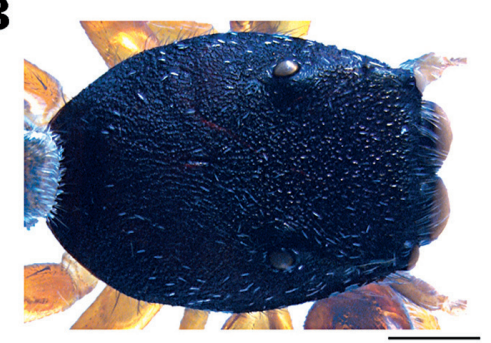

C

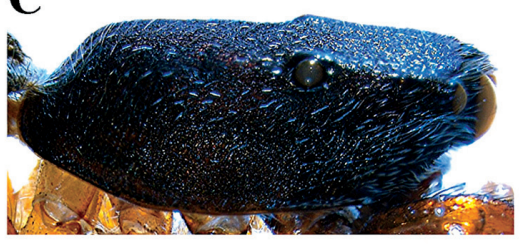

D

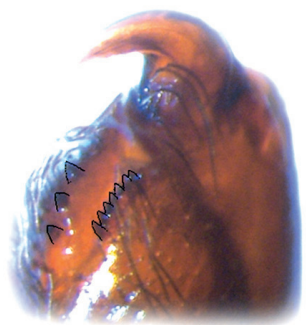

E

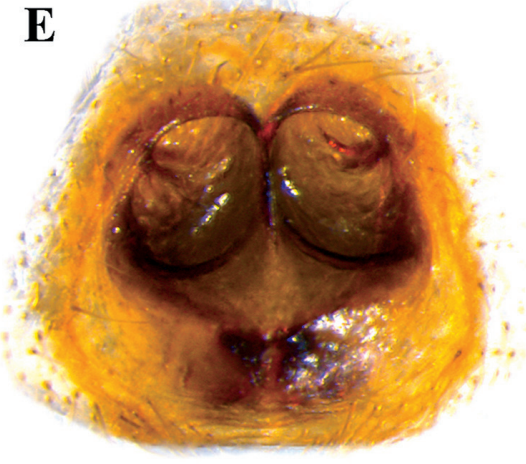

F

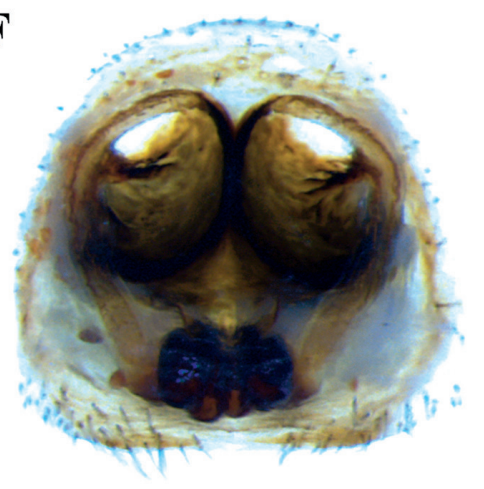

Fig. 2. Piranthus decorus Thorell 1895, female. A, dorsal view; B, carapace, dorsal view; C, same, lateral view; D, left chelicera; E, epigyne, ventral view; F, vulva, dorsal view. Scales $=1 \mathrm{~mm}\left(\mathrm{~A}^{-} \mathrm{C}\right) ; 0.1 \mathrm{~mm}\left(\mathrm{D}^{-\mathrm{F}}\right)$.

A
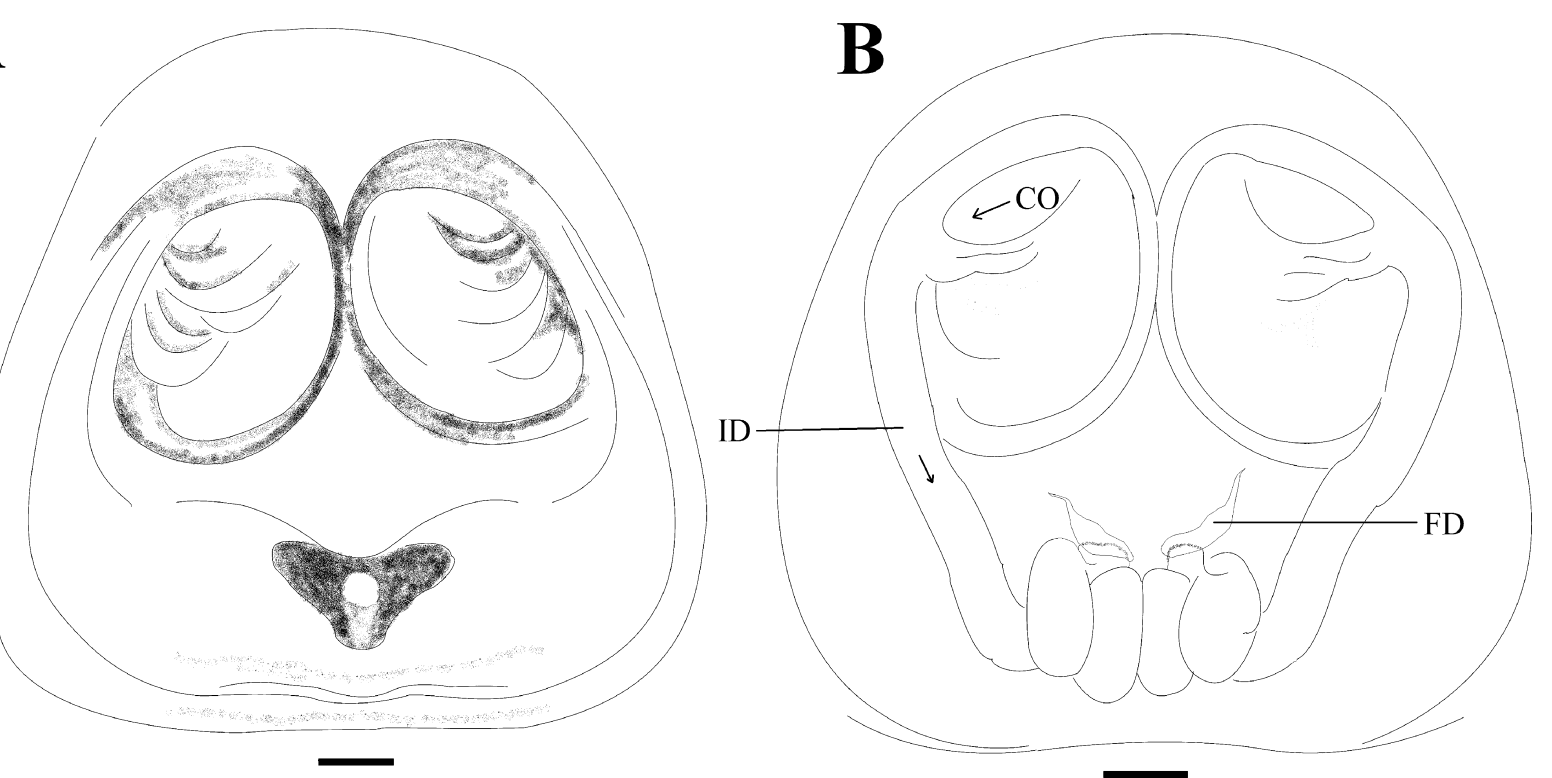

Fig. 3. Piranthus decorus Thorell 1895, female. A, epigyne, ventral view; B, vulva, dorsal view. Scales $=0.1 \mathrm{~mm}$. Abbreviations: CO — copulatory opening, FD — fertilization duct, ID — insemination duct. 

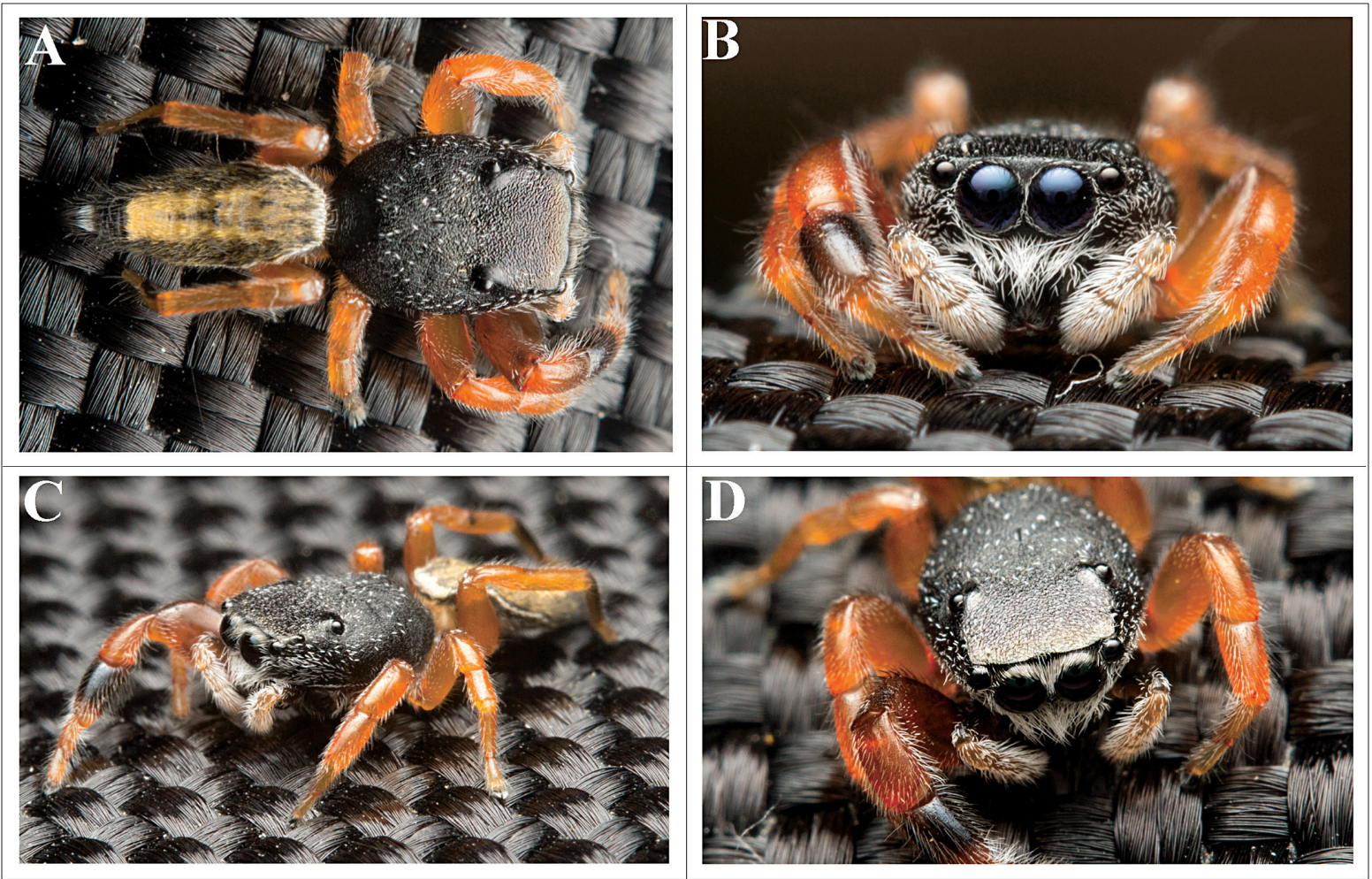

Fig. 4. Piranthus decorus Thorell 1895, female (fresh specimen). A, dorsal view; B, anterior view; C, antero-lateral view; D, antero-dorsal view.

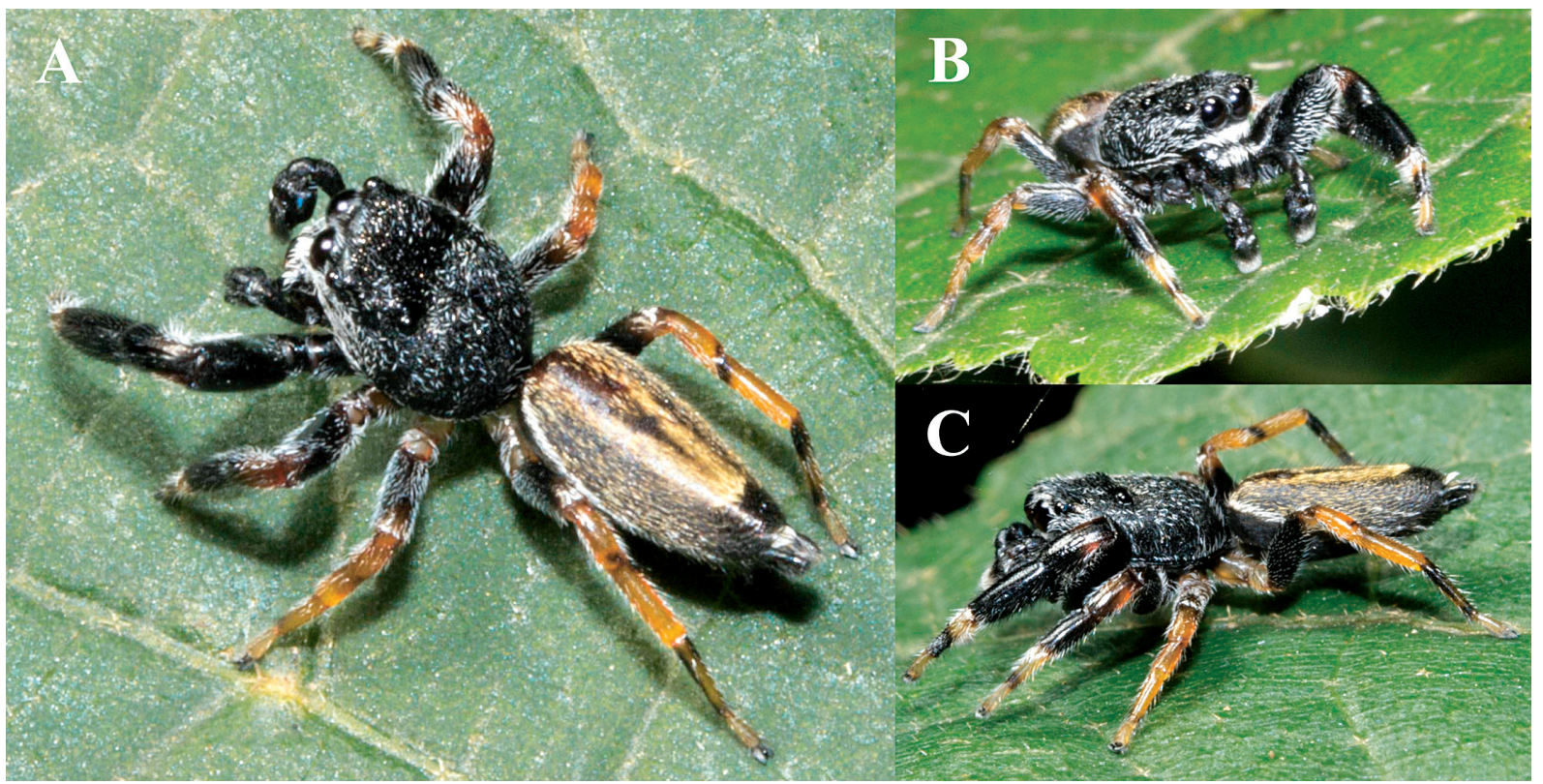

Fig. 5. Piranthus sp., male. A, dorso-lateral view; B, anterior view; C, lateral view. Images taken by Rajesh V. Sanap from Aarey Milk Colony on 11 August 2015. 
Natural History. The specimen examined was collected during the monsoon (June-July) from low vegetation in the Aarey Milk Colony. The vegetation during this period is thick and primarily dominated by seasonal herbs.

\section{Acknowledgement}

We express our thanks to Dr Krushnamegh Kunte, National Centre for Biological Sciences (NCBS), TIFR, for allowing us to use the stereo microscope facility and deposit specimens. Thanks to Dr Varad Giri for his valuable remarks on preparing the plates. Thanks to Ms. Anuradha Joglekar for help in editing and preparing the map. Thanks to Mr. Ashish Jadhav who helped in the field work. Sincere thanks to Dr Wayne Maddison for help in identifying the species. We are grateful to the two anonymous reviewers and Dr Takahidae Kamura for their valuable suggestions which greatly helped improve the manuscript.

\section{References}

Prószyński, J. 1984. Atlas rysunków diagnostycznych mniej znanych Salticidae (Araneae). Wyższa Szkola Rolniczo-Pedagogiczna, Siedlcach, 2: 1-177.

Prószyński, J. 2016. Salticidae (Araneae) of the world, Chapter II. Available at http://www.peckhamia.com/salticidae/index.html, accessed on January 23, 2017.

Simon, E. 1900. Descriptions d'arachnides nouveaux de la famille des Attidae. Ann. Soc. Ent. Belg., 44: 381-407.

Thorell, T. 1895. Descriptive catalogue of the spiders of Burma. London, pp. 1-406.

World Spider Catalog 2017. World Spider Catalog. Natural History Museum Bern, online at http: //wsc.nmbe.ch, version 18, accessed on January 28, 2017.

Received March 10, 2017 / Accepted May 10, 2017 